\title{
NOTAS SOBRE EL TEATRO ESPAÑOL EN LISBOA EN LA SEGUNDA MITAD DEL SIGLO XIX
}

\author{
NOTES ON SPANISH THEATER IN LISBON \\ IN THE SECOND HALF OF THE 19th CENTURY
}

\author{
Pilar NICOLÁS MARTÍNEZ \\ Universidade do Porto - DEPER \\ pilarnicolasletras@gmail.com
}

Resumen: Este artículo tiene como propósito ofrecer un panorama general sobre las representaciones teatrales españolas que subieron a escena en los teatros de Lisboa entre 1850 y 1899. Para ello, se analizará el número de compañías españolas que visitaron la ciudad, tanto de teatro declamado como lírico, así como sus periodos de estancia. También aparecerán ejemplos de la recepción que estos artistas y sus actuaciones tuvieron en el público, a través de las críticas publicadas en la prensa. Por último, se mencionará el repertorio de obras españolas interpretadas en Lisboa, así como las adaptaciones que se realizaron de esas piezas al portugués.

Palabras clave: Teatro español. S.XIX. Portugal. Lisboa. Zarzuela.

Abstract: This article aims to provide an overview of the Spanish plays performed between 1850 and 1899 at theatres in Lisbon. In order to do so, we will analyze the Spanish theater companies that visited the city, as well as their period of stay, noting that these companies were both musical and traditional. The reception that these artists and their performances had in the audience will be analysed through the remarks of journalists during the period in question. Finally, the Spanish repertoire performed in Lisbon, and the translations that were made into Portuguese will be mentioned.

Key Words: Spanish Theater. 19th century. Portugal. Lisbon. Zarzuela. 
Al comenzar a investigar sobre la representación del teatro español en Lisboa durante el siglo XIX', la primera impresión parecía apuntar a que no había existido una relación teatral relevante entre los dos países, dado que hay escasos estudios actuales que aborden el tema. Sin embargo, al consultar los diarios lisboetas y la prensa teatral publicada en esa época, se puede constatar: la estancia regular de compañías teatrales españolas en la capital portuguesa, un extenso catálogo de piezas españolas representadas en la ciudad, críticas teatrales escritas por los folletinistas portugueses comentando la interpretación de tal o cual cantante, actor o puesta en escena de una obra española, el nada despreciable número de traducciones de, sobre todo, libretos de zarzuela adaptados al portugués, la positiva valoración de las visitas a Lisboa de personalidades del teatro lírico decimonónico como Barbieri, José Rogel, Tomás Bretón, la tiple Elisa Zamacois o la de destacados actores de teatro declamado del último tercio del siglo como Antonio Vico, María Tubau o María Guerrero. En fin, un panorama más amplio y complejo de lo que parecía a simple vista y que ayuda a profundizar en el conocimiento que existe en la actualidad sobre las relaciones culturales y literarias que mantuvieron Portugal y España en ese periodo. Para ello, se adopta un enfoque que no se centra en las relaciones entre políticos, intelectuales y escritores de ambos países en torno al iberismo, sino que muestra otra cara más cotidiana o popular: la de la variedad y continuidad de las manifestaciones teatrales españolas como espectáculo de diversión y evasión en la ciudad de Lisboa.

Antes de empezar de lleno con la exposición es importante explicar que este trabajo se integra en un amplio proyecto de investigación promovido por los responsables del Centro de Investigación de Semiótica Literaria, Teatral y Nuevas Tecnologías -SELITEN@Tvinculado a la Universidad Nacional de Educación a Distancia (cuyas actividades pueden verse en http://www.uned.es/centro-investigacion-SELITEN@T), dirigido por el prof. José Romera Castillo. De entre las varias líneas de investigación que aborda el SELITEN@T se encuentra la de la reconstrucción de la vida escénica en España (desde la segunda mitad del siglo XIX hasta nuestros días) y la presencia del teatro español en Europa y América. "Siempre atendiendo a las puestas en escena de las obras teatrales, como espectáculo artístico, social y cultural", tal como explica el profesor José Romera Castillo en su libro Pautas para la investigación del teatro español y sus puestas en escena (2011: 103).

Para comenzar con el tema es conveniente poner de manifiesto algunos datos generales con el propósito de ofrecer una idea global. Durante la investigación se localizaron setenta y tres compañías teatrales españolas que actuaron en Lisboa entre

1 Para mayor información, remito a mi tesis doctoral, El teatro español en Lisboa en la segunda mitad del siglo XIX (defendida en la UNED, el 12 de enero de 2016), que puede leerse completa en la web del SELITEN@T, gracias a la amabilidad de su director, el Dr. José Romera Castillo (http://www2.uned.es/centroinvestigacion-SELITEN@T/pdf/Teatro_espanol_Lisboa_1850-1899.pdf). 
1850 y 1899 , de las cuales sesenta eran de zarzuela (de ellas buena parte se acompañaba también de un grupo de baile), seis presentaban un repertorio mixto de piezas declamadas y líricas, y siete eran exclusivamente de teatro declamado.

Es una cantidad que como promedio daría más de una compañía por año, aunque hay que aclarar que la presencia de intérpretes españoles en la ciudad aunque es constante va creciendo a medida que avanza el siglo. Por ejemplo, en la década de 1850 a 1859 actuaron seis, en la década de los años 60 otras seis, en los años 70 doce, en los 80 catorce y en los 90 treinta y cinco. Pese a que la diferencia en número crece visiblemente en la última década, también hay que puntualizar que las compañías que actuaron entre 1890 y 1899 tenían estancias mucho más cortas que en décadas anteriores.

A estas compañías profesionales se les puede sumar una compañía española de aficionados denominada Sociedad Lírico-dramática de los emigrados españoles, que en septiembre de 1876 ofreció algunas funciones representando en dos ocasiones un drama histórico de fuerte contenido político (Penas Varela, 2003: 1931) Carlos II, el Hechizado (1837) de Antonio Gil y Zárate. También fueron numerosas las compañías portuguesas que actuaron en los principales teatros de la ciudad interpretando traducciones de piezas españolas. La mayoría fueron de teatro lírico, no obstante se localizan de vez en cuando traducciones de obras declamadas. Por ejemplo, el grupo de actores del Teatro D. Maria Il adaptó en 1896 con extraordinario éxito el drama de Joaquín Dicenta Juan José (1895), que llegó incluso a contar con una parodia de Eduardo Fernandes titulada José João que subió a escena en el Teatro Príncipe Real.

A su vez, también, hay que mencionar algunas compañías italianas como la de Antonio Scalvini (en 1882), Aristide Gargano (en 1894), Rafael Tomba (entre 1894 y 1895) o Emilio Giovannini (en 1895) que incluían en su repertorio piezas líricas de compositores y libretistas españoles como Marina con música de Emilio Arrieta y letra de Francisco Camprodón, La Gran Vía de Federico Chueca y Joaquín Valverde y libreto de Felipe Pérez y González o El dúo de la Africana de Manuel Fernández Caballero y texto de Miguel Echegaray.

El abrumador predominio de las compañías que representaban teatro lírico español se debe a dos factores. El primero está relacionado con la afirmación con la que José Luis Temes comienza su libro, publicado en 2014, El siglo de la zarzuela. 1850-1950:

No creo exagerado afirmar que la zarzuela fue el movimiento artístico de mayor dimensión y arraigo social de la historia de la cultura española. Con esta aseveración no estoy diciendo, claro es, ni que la zarzuela haya sido el fruto artístico de mayor envergadura que haya dado España ni que otros movimientos no hayan aupado el arte español a cimas de mayor excelencia. Pero sí creo que, si el calado de un fenómeno cultural puede medirse por el 
modo en que lega para la historia una manera de sentir y pensar de un pueblo, y por la pervivencia en el tiempo de tal fenómeno, nunca antes ni después la sociedad española se ha visto mejor identificada en sus ideales yen sus modelos -para bien y para mal, no hay duda de ello-que como lo fue la España de la zarzuela (Temes, 2014: 11).

Si la zarzuela (nueva, moderna o restaurada, es decir, no barroca), surgida en el XIX como espectáculo ciudadano fue en la segunda mitad del siglo el entretenimiento principal en España y viajaba con inmediatez a Hispanoamérica, se recogen suficientes muestras de que, asimismo, gozó de gran éxito en Portugal.

En el interesante libro ya citado de José Luis Temes, se comenta que la zarzuela "nunca logrará asiento en otros países europeos (y eso que sus presencias puntuales fueron más frecuentes de lo que a veces creemos)" (2014: 18). En este caso me permito matizar las palabras del maestro, dado que en todo Portugal la presencia no fue puntual sino continua. No obstante, entiendo que puedan usarse en contra de esta afirmación precisamente los datos que se han aportado unos párrafos antes, esto es, que en Lisboa fueron seis las compañías que actuaron en los años 50 y de ellas concretamente dos son en exclusiva de zarzuela, frente a las más de treinta en la última década del siglo. Y es cierto que el gusto por la zarzuela va creciendo en el país vecino, pero también hay que aclarar que la zarzuela no llega a Lisboa representada por compañías españolas sino a través de la adaptación y traducción que realiza la compañía portuguesa del Teatro D. Maria Il de la pieza en dos actos El duende, compuesta en 1849 por Rafael Hernando con libreto de Luis de Olona.

Se adaptó al portugués con el título O Duende y se estrenó el 2 de junio de 1850, es decir, tan solo un año después de su primera función en el Teatro de Variedades de Madrid (el 6 de junio de 1849), y rápidamente se convirtió en uno de los grandes éxitos teatrales de la segunda mitad del siglo XIX en Lisboa. En el Dicionário do teatro português (1908), António de Sousa Bastos la incluye en la sección titulada: "Successos Theatraes. Relação das peças de maior exito em Portugal, já pelo agrado, já pelo grande numero de representações". A propósito de esta obra comenta "representada no theatro de D. Maria II em 1850. Reprises nos theatros das Variedades e Trindade" (Bastos, 2006: 297). Leyendo la sección de espectáculos de los diarios lisboetas, se recogen, entre 1850 y 1882, noventa representaciones de esta zarzuela -aunque debe especificarse que treinta y cuatro de ellas se representaron en el año de su estreno-; sin embargo, es muy probable que se alcanzasen las cien representaciones y ello sin contar las funciones en otras ciudades portuguesas. Debido a este éxito de público, la continuación El Duende. Segunda parte compuesta en 1851 por los mismos autores, Hernando y Olona- fue estrenada en Lisboa 
tan solo cinco meses después que en Madrid, el 31 de julio de 1851, e interpretada por la misma compañía portuguesa que subió a escena la primera parte.

Otras piezas de teatro lírico español traducidas y representadas por compañías portuguesas fueron, por ejemplo: Colegialas y soldados (1849) -en portugués conocida con el título Glória e amor- de Rafael Hernando y texto de Mariano Pina Bohigas en 1856, El campamento (1851) de José Inzenga con libreto de Luis de Olona en 1852, El valle de Andorra (1852) de Joaquín Gaztambide y texto de Luis de Olona en 1875, Catalina (1854) -titulada A Estrela do Norte- también con música de Gaztambide y texto de Luis de Olona en 1865, El sargento Federico (1855) de los maestros Francisco Asenjo Barbieri y Joaquín Gaztambide con libreto adaptado de Luis de Olona en 1872, El diablo en el poder (1856) de Barbieri y letra de Francisco Camprodón en 1862, Amar sin conocer (1858) con música de Barbieri y Gaztambide y letra de Luis de Olona en 1871, El secreto de una dama (1862) de Barbieri y texto original de Luis Rivera en 1873, Las amazonas del Tormes (1865) con música de José Rogel y texto arreglado del francés por Emilio Álvarez en 1872, El joven Telémaco (1866) de José Rogel y libreto de Eusebio Blasco en 1867, El último figurín (1873) con música de Rogel y libreto de Ricardo Puente y Brañas en 1881, La Gran Vía (1886) de Federico Chueca y Joaquín Valverde y libreto original de Felipe Pérez y González en 1887, El rey que rabió (1891) -traducido como El-Rei damnado- de Ruperto Chapí y libreto original de Miguel Ramos Carrión y Vital Aza en 1893, El dúo de la africana (1893) con música de Manuel Fernández Caballero y texto de Miguel Echegaray en 1894. La mayor parte de estas obras subió a escena en el Teatro da Trindade y, en menor número, en el Teatro da Rua dos Condes.

Con respecto a las compañías llegadas de España que actuaron en Lisboa, la primera que incluía teatro musical en su repertorio fue la Compañía española del Teatro D. Fernando, que actuó entre el 14 de julio y el 19 de septiembre de 1851 y representaron la ópera cómica española, en dos actos, El tío Caniyitas o El mundo nuevo de Cádiz (1849), con música de Mariano Soriano Fuertes y letra de José Sanz Pérez. No obstante, la primera formación exclusivamente de zarzuela que representó en la capital portuguesa fue la Compañía española lírico dramática y de danza, cuyo director era Antonio Campoamor. Este barítono ya gozaba de prestigio, pues había formado parte de la compañía del Teatro de la Cruz de Madrid, donde estrenó algunas de las primeras zarzuelas románticas en 1849 y a inicios de los cincuenta pasó a interpretar para la compañía creada por la Sociedad Artística en el Teatro del Circo (Casares Rodicio, 2006, I: 369).

Volviendo sobre las razones de la preponderancia de la presencia de compañías de teatro lírico frente a las de teatro declamado, los motivos tienen que ver, asimismo, con la diferencia de idiomas y de elementos culturales o sociales difíciles de descodificar, por falta de referentes, para el público portugués. A propósito es interesante el ejemplo de un grupo de teatro declamado que visita Lisboa en 1850: la Compañía española de los 
Académicos de Madrid. Sobre ellos se publicó el 13 de marzo de ese año en el diario $A$ Revolução de Setembro una noticia en la cual se anunciaba su estreno, al día siguiente, y lo más interesante es que el periodista (se desconoce el nombre) celebraba la posibilidad de poder ver en Lisboa una nueva escuela de declamación y muestras de la literatura española del momento; señalándola como una de las más bellas y fecundas de Europa, a pesar de ser casi desconocida en Portugal. Concluía diciendo que se esperaba gran concurrencia en las funciones y un éxito brillante.

Parece que los buenos augurios del periodista no se cumplieron, dado que representaron tan solo seis piezas en el mes y medio que estuvieron en la ciudad. Suponemos que el motivo tiene que ver con la crítica negativa, de autor desconocido, que a inicios de abril se puede leer en un semanario de espectáculos: "bien sea por la diferencia del idioma o por la originalidad en la declamación, el público no se interesó por los estudiantes españoles" (Revista dos Espectáculos, 1-04-1850).

En relación con los libretos de zarzuela, a veces se encuentran también inconvenientes en este sentido, pero se resalta que la música ayuda a superar las incomprensiones del argumento. Por ejemplo, la crítica sobre la zarzuela bufa en tres actos Los órganos de Móstoles con libreto de Luis Mariano de Larra y música del maestro José Rogel, que se presentó en Lisboa en 1868, comentaba lo siguiente:

A peça [...] fez verdadeiro furor, e comtudo escapam a todo o momento ao nosso publico, nem podia deixar de ser, as graças de intenção, os disfarces de ironia de que está cheia; ha porém uma graça geral que é de todos os paizes, a idéa, o espirito, o atticismo, e os espectadores comprehenderamIhe o alcance e applaudiram. A peça intitula-se Los órganos de Móstoles por haver em Móstoles um orgão celebre cujas teclas desafinam entre si que não ha entender-se com ellas. Já o leitor vê disto que a primeira cousa que não percebeu da peça... foi logo o titulo [...] (Rev. Set., 2-05-1868)2.

En 1889 se localiza otra crítica, aún más explícita, que dice al respecto:

Nos parece [El diablo en el poder] que fue mal escogida para el Colyseu, donde faltan todas las condiciones acústicas. Problema que se deja sentir sobre todo en la declamación, pues pocos felices lograron oírla. Así el primer acto que constaba casi todo de canto fue bien recibido por el público, el segundo, en cambio, en que abundaba la declamación fue recibido con manifiesto desagrado. Con todo, destacaron Matilde Franco y Vázquez, tan queridos ya

2 En todos los casos en los que en este trabajo se transcribe una cita en portugués, se mantiene la ortografía del texto original. 
por el público, de lo que se deduce que las quejas se deben exclusivamente a la elección de la pieza y lo que ocurrió con esta va a pasar con todas en las que la música no predomine (Rev. Set., 5-06-1889)³.

Es pertinente profundizar un poco más sobre la duración media de la estancia de las compañías españolas en Lisboa que solía ser de dos o tres semanas para las de teatro declamado -a pesar de que, por ejemplo, la Compañía española dramática y de zarzuela Vergara dio tan solo un par de funciones en febrero de 1875, en las que representó Don Juan Tenorio de Zorrilla; obra que en el tercer tercio del siglo solo había subido a escena en Lisboa una vez antes en enero de 1857-, y de alrededor de tres meses para las de zarzuela. Sin embargo, se dan casos especiales como el de las formaciones líricas que actuaron en el Teatro dos Recreios Whittoyne, pues desde su inauguración el 6 de noviembre de 1875 (véase la figura no 1 en el Anexo) este espacio teatral se especializó en ofrecer espectáculos de teatro musical español, por lo que hasta 1880 actuaron seis compañías líricas españolas. De ellas, una estuvo un año completo; otra, once meses, y otra, siete. Sumando todo esto al tiempo que permanecieron las otras tres, se trata de casi cuatro años seguidos de espectáculos de zarzuela en el Whittoyne.

Como se ha referido con anterioridad, en la década de 1890 crece de forma exponencial el número de compañías que actúan en la ciudad, pero a la vez el total de días de su estancia disminuye ostensiblemente. Con todo, continúa habiendo algunas que actuaron entre dos y tres meses, como la recurrente Compañía española de zarzuela y baile de Eduardo Ortiz, que representó en el Teatro D. Amélia (actual Teatro Municipal São Luiz, situado en el Chiado) en 1894, 1895, 1897 y 1898; pero el resto no suelen llegar al mes e, incluso, la de José Martinvalle solo actuó un día.

Sobre las formaciones de actores que dieron muy pocas funciones en Lisboa debe resaltarse que se encontraban de paso; algunas de ellas porque se dirigían a otras ciudades portuguesas o españolas cerca de la frontera y otras, las más prominentes, porque iban a embarcar con destino a América (o porque acababan de desembarcar). Al respecto conviene recordar la importancia del puerto de Lisboa.

Relacionado con este último motivo se lee la siguiente noticia, a propósito de la visita de la Compañía española de zarzuela dirigida por Gaspar Galinier y Juan Redondo:

COMPANHIA DE ZARZUELA. Chegou hoje a companhia de zarzuela, que vem embarcar para a America e que aproveitando a sua passagem por Lisboa, effectua dez recitas no Real Colyseu. A estreia realisa-se no sabbado. Amanhã publicaremos o elenco da companhia (D. Ilu., 20-02-1896).

3 La traducción es nuestra. 
Pese a que la prensa no aporta datos concretos al respecto, se supone que la forma de transporte preferida por las compañías era el barco, pues existía un paquebote que unía Cádiz con Lisboa y, en el otro sentido, Oporto con la capital. Los anuncios con los días y horarios son frecuentes en la última página de los diarios. En este sentido, y aunque no se trate de una compañía española, es ilustrativa la siguiente noticia sobre un grupo artístico escocés, dado que aporta datos a favor de este supuesto:

THEATRO DO GYMNASIO DRAMATICO. A familia artistica Sawyer. Notabilidade europea, única no seu genero conhecida pela denominação de celebres campanologos escocezes.

A direcção d'este theatro, constando-lhe o enthusiasmo com que estes artistas têem sido acolhidos nos principaes theatros aonde têem dado concertos com a sua collecção de 150 campainhas, conseguiu que de Cadiz, aonde se acham para seguirem viajem para a America, viessem de passagem a esta capital [...] (D. Gov., 13-04-1864).

Sin embargo, también, son numerosos los artistas que llegan de Madrid. Con respecto a las conexiones con la capital española, es curioso el testimonio que ofrece el librito Madrid de Manuel Pinheiro Chagas (1842-1895), donde el prolífico escritor, periodista y político portugués narra su viaje de Lisboa a Madrid del 22 al 31 de octubre de 1871. En este caso, lo que interesa es la información relativa al trayecto que realizó con sus amigos en "caminho de ferro" en un "comboyo de recreio", en el que cada compartimento disponía de espacio para diez personas. El itinerario partía de Lisboa remontando el Tajo para llegar a Santarém, descendía por el interior con destino a Elvas, cruzaba la frontera por Badajoz parando en Montijo y Almorchón, llegaba a Ciudad Real, después Aranjuez y, por fin, Madrid, tras treinta y cinco horas de viaje (Chagas, 1872: 1-19). Un mismo recorrido en ferrocarril que realizaría buena parte de los intérpretes españoles que se desplazaron a Lisboa en tren.

Otro hecho que se ha apreciado durante la investigación es que desde 1857 se instaura en Lisboa que la temporada de zarzuela es en primavera y verano, cuando ya había terminado la programación de ópera del Real Teatro S. Carlos. De ahí que las compañías solían llegar después de la semana de Pascua y permanecían hasta junio o julio, posteriormente -si habían tenido éxito de público en la capital-, se desplazaban hasta Oporto donde las primeras actuaciones comenzaban a inicios de verano. A propósito, encontramos una crítica del célebre escritor portugués Ramalho Ortigão (1836-1915), publicada en el Jornal do Porto donde en 1866 comentaba lo siguiente: 
A opera é a mulher das salas, decotada, palida, morbida, franzina, alumiada pelo clarão das luzes, baloiçada pelo perfume dos bouquets que se agitam no turbilhão das valsas. A zarzuela é a rapariga travessa, que salta ao ar livre, debaixo das larangeiras, ao som das castanholas e dos pandeiros, no espaço de tempo que medeia entre um alegre jantar e uma ceia mysteriosa.

A opera é o prazer do inverno. A zarzuela é a companheira do verão. Nós pela nossa parte declaramos que morremos pela opera desde novembro até fevereiro, e que adoramos a zarzuela desde junho a setembro.

Se algum dia fizermos um repertorio, não nos ha de esquecer o especificar isto. No $1^{\circ}$ de dezembro semeia o theatro lyrico. No $1^{\circ}$ de junho planta a zarzuela (Rev. Set., 6-06-1866).

No obstante, hay temporadas en las que cambia esta tendencia. Por ejemplo, la compañía de Juan Molina y el director de orquesta valenciano Juan García Catalá estuvo actuando durante varios años seguidos entre Galicia, Oporto, Coímbra y Lisboa, y pasó en la capital los meses de febrero a abril de 1875. Después, el periodo ya mencionado del Teatro dos Recreios Whittoyne en el que cuatro compañías representaron entre noviembre y febrero de 1875 a 1880; y en la última década, por ejemplo, se encuentra en diciembre de 1892 y enero del 93 la Compañía española de zarzuela de Pablo López, o la del maestro Guillermo Cereceda que visitó Lisboa durante varios años y en una de las ocasiones en invierno de 1895.

Acerca de la recepción que tuvieron las compañías españolas que actuaron en la ciudad, vamos a aproximarnos a dos casos de éxito: el primero, el de la Empresa española de zarzuela y baile que actuó en el Teatro Circo de Price de Lisboa en 1865 y, a continuación, la primera visita de la Compañía dramática española de Antonio Vico que estuvo en el Teatro do Ginásio y en el Real Coliseo, en 1892.

Para empezar, veamos cómo ilustraba Gustavo de Matos Sequeira en su libro Depois do terremoto. Subsídios para a história dos bairros ocidentais de Lisboa el paso por la capital de la Empresa española de zarzuela y baile cuyo director de escena era Isidoro Pastor (tenor cómico ya conocido y apreciado en Lisboa desde 1859):

No ano de 1865, em vez de cavalinhos e feras, de trapézios e arames, estava no Price a companhia de zarzuela hespanhola de Francisco Mela, exibindo zarzuelas de Arrieta e Barbieri. A principal figura da companhia era a primeira tiple Emilia Zamacois, a telhuda Zamacois que endoideceu metade dos lisboetas. A outra metade endoidecera, por seu turno, à conta da señorita Luisa Medina, galante e formosíssima bailarina castelhana. 
Olímpio de Freitas e Júlio Cesar Machado, os dois talentosos folhetinistas, disseram maravilhas dessa estonteante creatura. Os seus bailes com $D$. Ambrozio Martínez, eram um assombro de sensualismo coreográfico. Quando em julho, ela e a Zamacois se foram embora, gelaram-se os corações alfacinhas apezar da ardência dêsse verão.[...] ¡Foram meses de delírio! (Sequeira, 1917, II: 465) ${ }^{4}$.

Efectivamente tuvieron tan buena aceptación que se leen en la prensa numerosas alabanzas sobre sus actuaciones, sobre todo refiriéndose al desempeño de la primera tiple absoluta Elisa Zamacois. A tal grado llegó el entusiasmo por la actriz y cantante que se vendieron, incluso, unos puros Zamacois. Suponemos que el nombre de la célebre cantante aparecería impreso en la vitola y en la caja.

Esta divertida idea surgió a partir de la crítica teatral publicada en el folletín Revista da semana que escribió Júlio César Machado en el nº 6876 de A Revolução de Setembro. En ella, tras comentar el hechizo que la cantante había causado en el público lisboeta, solicitaba en un par de ocasiones "Cada um de nós exclama: Haja charutos Zamacois!". El texto decía, no sin cierta ironía particularidad de este autor, así:

Oh! Paiz sem imaginação, oh! Podengo, oh! Pobre diabo de paiz! Pois ha cinco dias que esta formosissima e festejada hespanhola produz no circo um phrenesi de enthusiasmo, que todos a applaudem enfeitiçados, velhos e moços, que todos vão em onda visita-la ao palco, apertar-lhe a mão ao camarim, adora-la nos bastidores.

Cinco dias! Em que não se tem feito outra coisa senão fallar nella, lêr-lhe o nome nos cartazes, celebra-la nas gazetas, apregoa-la, canta-la, eternisala; ha cinco dias! e ainda não houve um abençoado estanqueiro que se lembrasse de chamar Zamacois a uns charutos quaesquer, que, por peiores que fossem, só por serem Zamacois nos pareceriam tabaco d'anjos! (Rev. Set., 25-04-1865).

Y, dicho y hecho: a partir del 2 de mayo y hasta aproximadamente el 20 de ese mes, comenzó a aparecer en el periódico citado un anuncio vendiendo tan evocador tabaco.

En el tiempo que permaneció Elisa Zamacois en Lisboa todo fueron lisonjas. Prácticamente apareció en todas las zarzuelas representadas por la compañía, pues su nombre era un reclamo para el público. La función en su beneficio tuvo lugar el sábado 27 de mayo e interpretó El estreno de una artista, de Gaztambide con libreto de Ventura

4 Repárese que en la edición de 1917 de este libro, se usaba en portugués el punto de exclamación de apertura. 
de la Vega, fragmentos de óperas, así como la canción Juanita o La perla de Aragón de Sebastián Iradier. La prensa indicaba que comenzó a las ocho de la tarde y terminó casi a las dos de la madrugada "durante todo esse tempo, o publico a reclama-la, as flôres a juncarem-lhe o palco, os poetas a canta-la, um delirio, um phrenesi, uma coroação, o despontar de uma immortalidade!" (Rev. Set., 30-05-1865).

Recordemos que Elisa Zamacois tenía 25 años en 1865 y ya era una intérprete consagrada en España, pues desde la temporada de 1857-58 estaba contratada por el Teatro de la Zarzuela y llegó a tener una estrecha relación profesional con su maestro Barbieri (Casares Rodicio, 2006, II.: 959). Después de esta acogida en Lisboa, la tiple regresó en otras dos ocasiones a la ciudad: 1866 y 1878.

En 1866 volvió a repetir el éxito del año anterior, siendo incluso mayor. Pues ya no estaba tan localizado en la admiración que un bando tenía por la tiple principal y el otro por la bailarina, sino que todo el conjunto de intérpretes fue muy admirado. A propósito se pueden ver varios de los carteles publicados por la compañía en OPSIS. Base Iconográfica de Teatro em Portugal, proyecto del Centro de Estudos de Teatro da Faculdade de Letras da Universidade de Lisboa 5 .

Sobre la visita de Elisa Zamacois en 1878 António Sousa Bastos escribe en Carteira do Artista una penosa e inexacta (en el año) apreciación: "Zamacois veiu mais tarde a Lisboa, em 1877, cantando no theatro dos Recreios. Estava velha e cansada; quasi não agradou" (Bastos, 1898: 152). En realidad, como se ha dicho, no estuvo en el 77, sino en el 78, actuando con la Cuarta compañía española de zarzuela del Teatro dos Recreios Whittoyne. Debutó el 25 de mayo, cuando el grupo ya llevaba mes y medio en la ciudad, con la obra La Marsellesa, donde interpretaba el papel de Flora. En realidad no permaneció demasiado tiempo, pues el 6 de julio dio su última función.

Centrándonos ahora en el teatro declamado, sabemos por el estudio El dramaturgo y los actores, de Carmen Menéndez Onrubia (1984: 296), que en 1892 el célebre actor Antonio Vico dejó Madrid y salió a provincias de gira con su propia compañía. Estuvieron por el noroeste español y actuaron en Oporto. No obstante, llegaron a Lisboa en verano desde Badajoz y entre el 27 de agosto y el 16 de septiembre representaron los dramas más representativos de la Restauración. De José Echegaray se subió a escena: Locura o Santidad (1877), El gran Galeoto (1881), Vida alegre y muerte triste (1885), De mala raza (1886) y Lo sublime en lo vulgar (1888). De Manuel Tamayo y Baus: La bola de nieve (1856) y Un drama nuevo (1867). También, algunas comedias como el juguete cómico en un acto y en verso Lagartijo (1890) de Carlos Sánchez.

5 Para ello, se debe entrar en la siguiente página de internet de OPSIS. Base Iconográfica de Teatro em Portugal, disponible en línea (http://opsis.flul.pt/Typology/Index [13/11/2016]), e introducir en el buscador el término "zarzuela". 
Su estancia tuvo bastante repercusión en los periódicos, por ejemplo, se observa que el Diário llustrado le dedicó la portada del n 6981, donde publicó incluso un retrato del actor y elogió su interpretación en la obra La muerte civil, traducción al español del drama de Paolo Giacometti. En concreto ese mismo día, viernes 2 de septiembre, se realizaba la fiesta artística en beneficio del propio Antonio Vico; en ella se representó por primera y única vez Vida alegre y muerte triste. Al día siguiente la prensa portuguesa se hizo eco del prestigio que el actor había logrado en España como iniciador de una nueva escuela declamatoria paralela a la de su compañero en el Teatro Español y competidor: Rafael Calvo. Al respecto se puede leer la siguiente crítica:

Vamos a trazar estas líneas, verdaderamente impresionados con el trabajo asombroso e inolvidable de Vico en el papel de Gaspar en Vida alegre y muerte triste.

El trabajo principal del extraordinario artista comienza en el $2^{\circ}$ acto y toma proporciones colosales en la escena del $3^{\circ}$ acto, en el que él mata al hombre que está a punto de seducir a su hija, mordiéndole, arañándole y estrangulándole al fin.

La muerte que Vico presenta en este drama fue de una realidad que dejó a los espectadores tan impresionados que al caer el telón, ya todos estaban de pie, vitoreando al eminente artista que fue llamado veinte veces al proscenio, agradeciendo Vico con frases conmovidas la ovación de la que estaba siendo objeto. João y Augusto Rossa le ofrecieron desde un palco un lindísimo y rico ramo enlazado con cintas con los colores de la bandera española. Vico fue felicitado en su camerino y recibió bastantes regalos (D. Ilu., 3-09-1892)6.

La compañía de Vico realizó, incluso, una función especial el 12 de septiembre en beneficio de las obras de caridad de la reina $\mathrm{D}^{\mathrm{a}}$ Amélia. En consecuencia, el rey Carlos I de Portugal galardonó al artista con las insignias del “Hábito de S. Tiago”, colocadas en un estuche junto a una carta del monarca dirigida personalmente al actor.

Vico regresó a Lisboa a finales de abril de 1898, donde repitió varias de las piezas que había representado en el 92 e incorporó a su repertorio el drama de Dicenta Juan José y Mariana de José Echegaray, pero en esta ocasión su visita no recibió la acogida de la precedente, pues llegó incluso a afrontar dificultades económicas para abandonar la ciudad (Bastos, 1898: 311).

Con todo, no solo son estos los artistas de reconocido prestigio en España que actuaron en Lisboa, sino que a lo largo de estos cincuenta años encontramos otros

6 La traducción es nuestra. 
intérpretes del panorama lírico como Antonia Uzal, que actuó en 1869; Enriqueta Toda, en 1870, 1883 y 1897; Romualda Moriones de 1876 a 1878; Dolores Franco de Salas en 1884; Dolores Perlá en 1875 y 1876; Rosendo Dalmau en 1870; Juan Salces en 1865, 1869, 1870 y 1879; Luis Carceller en 1875 y 1876, Isidoro Pastor en 1859, 1865 y 1866 o el barítono Manuel Cresci (Cotarelo, 2000: 681) o Crescj (Casares Rodicio, 2006, T.I.: 573) en 1859 y 1866.

Mención especial haremos a la estancia en 1868 de Francisco Arderius que en Lisboa denominó a su empresa Compañía de los verdaderos Bufos Madrileños, dado que el año anterior habían representado ya en la ciudad unos Bufos Madrileños cuyo director era el bailarín Manuel Guerrero, marido de la internacionalmente célebre bolera Petra Cámara. Con respecto a esta visita de Arderius, ya recogida por Emilio Casares Rodicio en su artículo sobre la historia del teatro de los Bufos (1997: 89), la prensa portuguesa estaba encantada en insistir sobre el origen portugués del audaz empresario y artista (Rev Set., 17-05-1868) y el articulista Júlio César Machado en su libro A vida alegre. Apontamentos de um folhetinista añade que "O pae d'esse Arderius era um portuguez de Elvas" (1880: 232). Este folletinista conoció a Arderius en el viaje que realizó a Madrid en 1866 y sobre la estancia de los Bufos Madrileños en Lisboa indica lo siguiente:

Logo depois um audacioso, meio hespanhol, meio portuguez, Arderius, que mais tarde veiu a Lisboa com uma companhia de Zarzuela perder o seu dinheiro no Circo de Price, fundou um theatro, a que deu o nome de Buffos madrilenos, e que tem sido o theatro da moda em Madrid (Machado, 1880: 231-232).

En los diarios consultados, nada nos dice que la estancia en el Circo de Price de Lisboa fuera ruinosa para Arderius. De hecho, se leen positivas valoraciones sobre el desempeño de la compañía y, en concreto, del propio Arderius. La crítica publicada sobre el día del estreno y escrita precisamente por Júlio César Machado afirmaba que no se apreciaba desigualdad entre los artistas, que las principales figuras desempeñaban sus papeles con profesionalidad y enfatizaba la figura de Francisco Arderius como un "artista de esfera superior". Asimismo, distinguía al maestro José Rogel pues decía hacer maravillas con la orquesta y, para terminar, señalaba que los coros valían "un triunfo" (Rev. Set., 14-04-1868).

Con respecto al famoso coro de las suripantas, llama la atención una crítica publicada en $A$ Revolução de Setembro en la cual se valoraba positivamente la primera representación de El joven Telémaco, aunque conviene recordar que la obra ya había sido interpretada el año anterior por la formación de los Bufos Madrileños de Manuel Guerrero con mucho más éxito. El caso es que en esta crítica se resaltaba la buena afinación del coro, el hecho de que cantaban bien, pero se puntualizaba que mejoraría considerablemente la puesta 
en escena si consiguiesen darle a su actuación una "mayor expresión seductora" y que nada les impedía levantarse, de uno de los lados, un poco la túnica; para concluir con este curioso comentario:

A austera Hespanha não Ihe permitiria taes liberdades, mas em quanto estão neste Portugal, faz tudo é aproveitar. Estendam as danças e encurtem as saias!... dizia um celebre empresario que fez fortuna por esse expediente (Rev. Set., 16-04-1868).

Con respecto a uno de los principales colaboradores de Arderius en su aventura bufa: el maestro José Rogel, bien conocido en Lisboa por sus composiciones, hay que señalar que regresó a la ciudad doce años más tarde, contratado como director de orquesta del Teatro da Trindade. En esta sala -situada en la Rua Nova da Trindade, entre el Chiado y el Bairro Alto, y que aún hoy continúa abierta-, se estrenó con gran aplauso (el 7 de octubre de 1880), Os dragões de El-Rei (adaptación al portugués de la ópera cómica francesa Les Mousquetaires au Convent) con música arreglada por el propio Rogel y libreto traducido por Francisco Palha y Eduardo Garrido. Asimismo, los actores portugueses del Trindade representaron varias obras del músico alicantino como Las amazonas del Tormes (1865), que ya subía a escena con cierta frecuencia desde 1872. También, se tradujo y representó en 1881 su zarzuela El último figurín (1873), con el título O último figurino, e incluso Rogel compuso dos partituras nuevas una para la pieza Romão e companhia, estrenada en febrero de 1882 y donde la actriz Florinda representaba a una andaluza con "muito chiste e salero", y otra para Um marido de sobejo, opereta en tres actos, que subió a escena en septiembre de 1882 precisamente la noche de la fiesta artística de Florinda.

Cuando José Rogel abandonó la dirección musical del Trindade en junio de 1883, la prensa decía que el público le echaría de menos porque "el maestro es muy estimado por los frecuentadores del Teatro da Trindade por su talento y cualidades" (Rev. Set., 2005-1883).

A pesar de que no se trate de un espectáculo teatral, no se puede dejar de mencionar la estancia en Lisboa de Francisco Asenjo Barbieri. Su visita estuvo relacionada no con su producción de zarzuelas, sino con su actividad concertística. El motivo es que fue contratado para ensayar y representar piezas de música clásica sinfónica con la orquesta portuguesa Associação Música 24 de Junho, formada por ochenta y cuatro intérpretes. Por esta razón, se puso a la venta un abono con derecho a asistir a tres de los llamados "Concertos Classicos" ejecutados a la una de la tarde en el Salão da Trindade, en los siguientes domingos del mes de abril de 1879: días 6, 20 y 27. El éxito de público y crítica fue tan grande que se organizaron un par de funciones más, una el miércoles 30 de abril 
y la otra el 16 de mayo; esta última a beneficio de un par de instituciones de beneficencia. Como explica el profesor Emilio Casares Rodicio:

La función de estos conciertos era parecida a la que tuvieron en los sesenta en Madrid, es decir, muchas de las obras que se interpretaron se dieron a conocer por primera vez, así varias sinfonías de Beethoven (Casares Rodicio, 1994: 364).

Así, los portugueses aficionados a la música advirtieron en su momento que Barbieri: "veio encher de luz o nosso pequeno mundo musical e despertar n'elle, o gosto pelas grandes composições classicas [...] até hoje pouquissimo conhecidas entre nós." (D. Ilus., 30-04-1879).

Para terminar, vamos a aproximarnos al repertorio en español que las setenta y tres compañías que visitaron Lisboa representaron en esos cincuenta años y que asciende a más de quinientas obras, tanto de teatro declamado como lírico. Y es que como definió con humor el crítico Christovam de Sá las compañías españolas sufrían de un "delirio de variedad"subiendo a escena una pieza nueva cada día (Rev. Set., 10-06-1883). El periodista exageraba un poco, pero sí que se ha calculado que la media era estrenar alrededor de diez obras diferentes cada mes, que sumadas a aquellas que se repetían por demanda del público supone alrededor de unas veinticinco mensualmente.

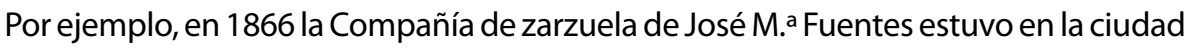
casi cuatro meses (del 31 de marzo al 22 de julio), en este tiempo estrenaron treinta y seis obras diferentes y se recogen en la sección de espectáculos un total de ciento tres piezas interpretadas por estos actores. No obstante, estas cifras variaron a lo largo de los años, pues según triunfaba en los palcos el género chico crecía lógicamente el número de obras representadas. De esta forma, en 1888 la primera vez que visitó Lisboa la Compañía del maestro Guillermo Cereceda -por cierto acompañado de su mujer la tiple Consuelo Montañés y de su hijo de cinco años Felipito Cereceda, que era ovacionado todas las noches que interpretaba el papel de $3^{\circ}$ Rata en La Gran Vía-, estrenaron treinta obras diferentes con un total de ciento sesenta y cuatro actuaciones en tres meses. Si nos situamos en 1896, la Compañía española de zarzuela de Ventura de la Vega, que llevaba un repertorio compuesto en exclusiva de obras líricas de género chico, subió nada menos que cuarenta obras diferentes en mes y medio, representando un total de ciento treinta y una piezas. En efecto, se debe concluir que se trataba de un "delirio de variedad".

En fin, a pesar de que el tema es muy extenso por la cantidad de datos que se han encontrado, se espera que al menos este panorama sirva para ilustrar el propósito expuesto al inicio: demostrar la intensidad de las relaciones teatrales españolas y 
portuguesas en este periodo, además de arrojar algo más de luz sobre los hábitos de representación de las compañías españolas que salían de gira fuera del país.

\section{ANEXO}

Figura 1

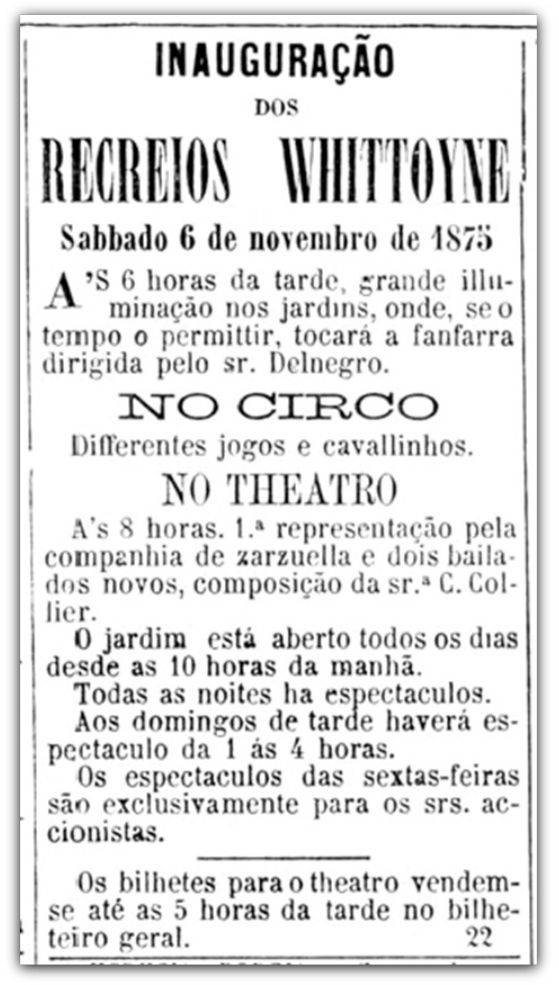

Diário llustrado. № 1063.

Sábado, 6 de noviembre de 1875. 
Figura 2

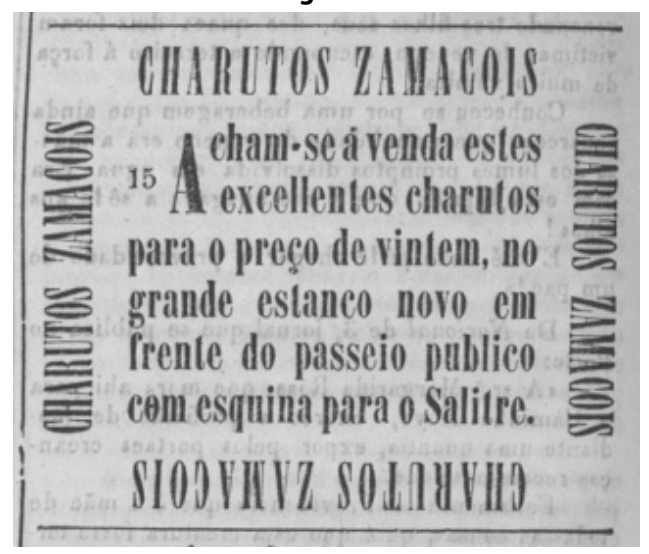

A Revolução de Setembro. Mayo 1865.

Figura 3

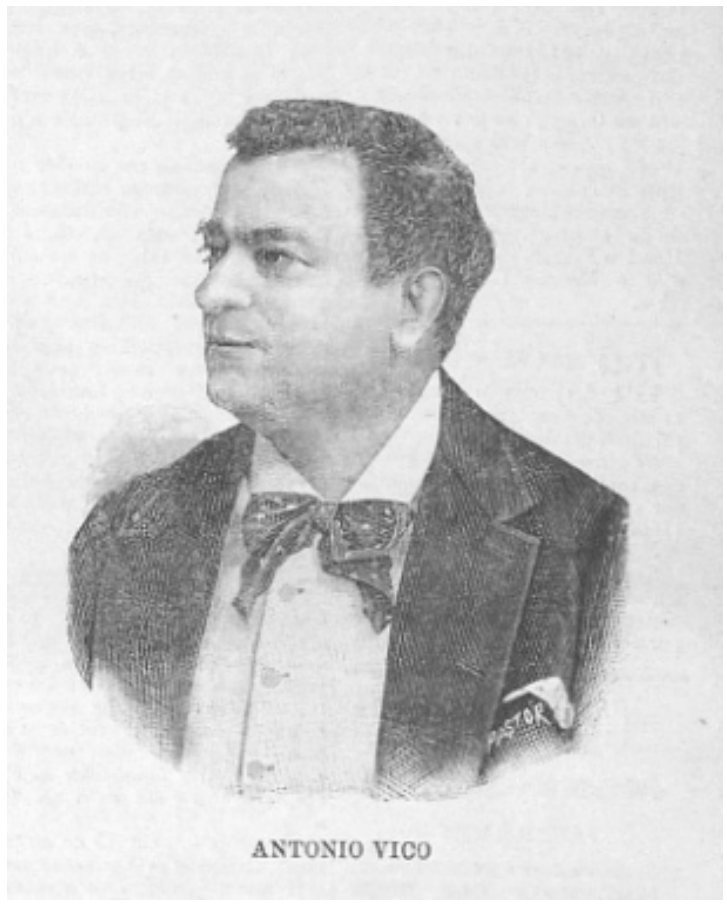

Diário llustrado. Viernes, 2 de septiembre de 1892. 


\section{REFERENCIAS BIBLIOGRÁFICAS}

BASTOS, A. de Sousa (1898). Carteira do Artista. Apontamentos para a História do Theatro Portuguez e Brazileiro, acompanhados de notícias sobre os principaes artistas, escriptores dramaticos e compositores estrangeiros. Lisboa: Antiga Casa Bertrand. Copia digital de University of Toronto Library, disponible en http://bit.ly/1L562q4 [13/11/2016]. (2006). Dicionário do teatro português. Edição fac-similada. Lisboa: Arquimides Livros [Facsímil de la edición de Lisboa: Imprensa Libânio da Silva, 1908].

CASARES RODICIO, E. (1994). Francisco Asenjo Barbieri. I. El hombre y el creador. Madrid: Instituto Complutense de Ciencias Musicales.

(1997). "Historia del teatro de Bufos, 1866-1881. Crónica y dramaturgia”. Cuadernos de Música Iberoamericana 2-3 (especial dedicado a La zarzuela en España e Hispanoamérica. Centro y periferia, 1800-1950), 73-118.

(2006). Diccionario de la zarzuela: España e Hispanoamérica. Emilio Casares Rodicio (dir. y coord. general). Tomos I y II. 2. ${ }^{\text {a }}$ ed. Madrid: Instituto Complutense de Ciencias Musicales.

CHAGAS, M. Pinheiro (1872). Madrid. Lisboa: Livraria de Caetano Simões Afra. Copia digital de University of Toronto Library, disponible en http://bit.ly/1JZ2h/E [13/11/2016].

COTARELOY MORI, E. (2000). Historia de la zarzuela o sea el drama lírico en España, desde su origen a fines del siglo XIX. Emilio Casares Rodicio (introd.). Edición facsímil. Madrid: Ediciones del ICCMU [Facsímil de la edición de Madrid:Tipografía de Archivos, 1934].

MACHADO, J. C. (1880). A vida alegre. Apontamentos de um folhetinista. Lisboa: Livraria Editora de Mattos Moreira \& Ca. Copia digital de University of Toronto Library, disponible en http:// bit.ly/2fvnXyE [13/11/2016].

MENÉNDEZ ONRUBIA, C. (1984). El dramaturgo y los actores. Epistolario de Benito Pérez Galdós, María Guerrero y Fernando Díaz de Mendoza. Anejos de la Revista Segismundo, no 10. Madrid: CSIC.

PENAS VARELA, E. (2003). “El drama romántico". En Historia del teatro español: del siglo XVIII a la época actual, t. II. Javier Huerta Calvo (dir.). Fernando Doménech Rico y Emilio Peral Vega (coords.). Madrid: Gredos.

ROMERA CASTILLO, J. (2011). Pautas para la investigación del teatro español y sus puestas en escena. Madrid: Universidad Nacional de Educación a Distancia.

SEQUEIRA, G. de Matos (1917). Depois do terremoto. Subsídios para a história dos bairros ocidentais de Lisboa, vol. II. Lisboa: Academia das Sciências de Lisboa. Copia digital de University of Toronto Library, disponible en $h t t p: / / b i t . l y / 2 f V q y 5 w$ [13/11/2016].

TEMES, J. L. (2014). El siglo de la zarzuela. 1850-1950. Madrid: Siruela. 


\section{PRENSA PERIÓDICA CITADA}

A Revolução de Setembro (1840-1901). Lisboa:Typ. J. B. da A. Gouveia. (Rev. Set.)

Diário do Governo (1835-1859). Lisboa: Imprensa Nacional. (D. Gov.)

Diário Ilustrado (1872-1910). Lisboa: Impr. de Souza Neves. (D. Ilu.)

Revista dos Espectáculos: supplemento à Revista Popular (1850). Lisboa: [Typ. ¿?]

Recibido el 12 de febrero de 2016.

Aceptado el 1 de noviembre de 2016. 
